\title{
Three-dimensional modeling of the casing effect in onshore CSEM surveys
}

\author{
Vladimir Puzyrev ${ }^{1, *}$, Eloi Vilamajo², Pilar Queralt ${ }^{2}$, Juanjo Ledo ${ }^{2}$ and Alex Marcuello ${ }^{2}$ \\ ${ }^{1}$ Curtin University, Department of Applied Geology, Western Australian School of Mines. Kent Street, \\ Bentley, Perth, Western Australia 6102 \\ ${ }^{2}$ GEOMODELS Research Institute, Departament Dinamica de la Terra $i$ de l'Ocea, Facultat de \\ Geologia. Universitat de Barcelona. C/ Marti i Franques s/n, Barcelona, Spain 08028 \\ *Corresponding author, vladimir.puzyrev@gmail.com, +61892664607
}

\begin{abstract}
The presence of steel-cased wells and other infrastructure causes a significant change of the electromagnetic fields that has to be taken into consideration in modeling and interpretation of field data. A realistic and accurate simulation requires the borehole casing to be incorporated into the modeling scheme, which is numerically challenging. Due to the huge conductivity contrast between the casing and surrounding media, a spatial discretization that provides accurate results at different spatial scales ranging from millimeters to hundreds of meters is required. In this paper, we present a full 3D frequency-domain electromagnetic modeling based on a parallel finite-difference algorithm considering the casing effect and investigate its applicability on the borehole-to-surface configuration of the Hontomín $\mathrm{CO}_{2}$ storage site. To guarantee a robust solution of linear systems with highly ill-conditioned matrices caused by huge conductivity contrasts and multiple spatial scales in the model, we employ direct sparse solvers. Different scenarios are simulated in order to study the influence of the source position, conductivity model and the effect of the steel casing on the measured data. Several approximations of the real hollow casing that allow for large reduction in number of elements in the resulting meshes are studied. A good agreement between the modeled responses and the real field data demonstrates the feasibility of simulating casing effects in complex geological areas. The steel casing of the well greatly increases the amplitude of the surface electromagnetic fields and thus improves the signal-to-noise ratio and the sensitivity to deep targets.
\end{abstract}

Keywords: Numerical modeling; Electromagnetics; Onshore CSEM; Monitoring; Casing effects; $\mathrm{CO}_{2}$ geological storage. 


\section{Introduction}

Over the last 15 years, the controlled-source electromagnetic (CSEM) method has become established in offshore hydrocarbon exploration (Constable 2010; Strack 2014). Academic studies have also demonstrated its potential for use in other geophysical contexts like gas hydrate exploration (Schwalenberg et al. 2005), exploration of geothermal resources (Muñoz 2014) or CO2 sequestration monitoring and time-lapse sensitivity analysis both onshore (Bhuyian et al. 2012) and in shallow sea (Kang et al. 2012). Integration of CSEM data into the reservoir characterization workflows and joint interpretation with other geophysical data types has been conducted (Macgregor 2012). Due to significant differences in the physics of seismic and electromagnetic (EM) methods, the information content from EM data is capable of improving the knowledge of subsurface rock property distributions obtained from seismic exploration. In some cases, CSEM is used as a complementary method to other EM techniques such as magnetotellurics or electrical resistivity tomography. A recent review of cooperative inversion of seismic and electromagnetic data and challenges associated with it can be found in Le et al. (2016).

The potential of EM methods for hydrocarbon and $\mathrm{CO} 2$ reservoir monitoring has intensified the development of CSEM techniques on land. Onshore experimental conditions are less advantageous compared with those in marine environments for CSEM exploration: prevalence of the airwave, inconvenient noise conditions and low penetration of the EM signals in the subsurface. Although the underlying physical principles are the same in onshore and offshore environments, relevant differences exist in terms of surveying methodology and data interpretation. EM methods often operate in unfavorable conditions and near the limits of depth penetration and resolution. As a result, novel land- based experimental configurations are being investigated in order to enhance the sensitivity of the method to deep structures and to improve the signal-to-noise ratio (e.g. Davydycheva and Rykhlinski 2011).

CSEM monitoring capabilities in onshore environment have been widely investigated with forward modeling studies (Colombo and Mcneice 2013; Zhdanov et al. 2013; Commer et al. 2015; Um et al. 2015). Key points of such experiments are the requirement of sufficient accuracy, the quantification of repeatability errors, and the sensitivity of the measurements to the subsurface changes (Streich 2016). Although many of the published synthetic feasibility studies concluded that land CSEM monitoring is suitable, only a small number of experimental applications have been carried out to date. In particular, onshore CSEM for $\mathrm{CO}_{2}$ monitoring applications include the $3 \mathrm{D}$ inversion of survey data collected across the $\mathrm{CO}_{2}$ storage formation 
at Ketzin, Germany (Grayver et al. 2014), and the modeling of the borehole-to-surface EM experiment at Hontomín, Spain (Vilamajó et al. 2015). Applicability of CSEM methods to monitor hydrocarbon production has been studied in Tietze et al. (2015) for the borehole-tosurface CSEM survey in the Bockstedt oil field in Germany. Time series acquired in onshore noisy areas may require the utilization of robust processing strategies to obtain high-quality data (Streich et al. 2013) or analysis of the polarization of the EM signal in order to detect and eliminate possible noisy signals (Escalas et al. 2013).

With the goal of enhancing time-lapse responses, the benefits of using instrumentation installed close to the geoelectrical target (borehole-to-surface or surface-to-borehole configurations) have been investigated in many of the published synthetic studies, e.g. Wirianto et al. (2010) and Colombo and McNeice (2013) for monitoring changes in hydrocarbon reservoirs during production. Vertical orientation of electric sources and receivers have the additional attractive property that they respond strongly to resistors as has been shown in multiple sensitivity studies (Streich 2016 and references therein). However, a critical issue of placing a source close or inside the well is the influence of metallic casing on CSEM data. A borehole with a steel casing extending from the surface to the deep target layer strongly influences the EM field in both borehole-to-surface and surface-to-borehole configurations. The casing effect can be much stronger than the target response and hence can mask the useful information. On the other hand, existing conductive infrastructure can be used as extended source signal transmitters thus allowing for amplification of the signal without installing new equipment. As recently demonstrated by Hoversten et al. (2016), a steel-cased well can significantly improve the sensitivity to the deep targets (commercially important depths of up to $4.5 \mathrm{~km}$ below the surface) and signal- to-noise ratio of the surface measurements.

The idea of using steel casings for exploration purposes goes back to the last quarter of the twentieth century. There is a vast literature on the effects of conductive steel casings on resistivity logging, cross-well, marine EM methods, surface-to-borehole and borehole-to- surface measurements. Examples of early works on the theory of the electric field in steel- cased boreholes and first experimental studies include the surface-to-borehole EM induction (Augustin et al. 1989), direct current resistivity (Kaufman 1990; Schenkel and Morrison 1994) and crosswell EM tomography (Wu and Habashy 1994) applications. Four decades of frequencies (from 0.1 to $1 \mathrm{kHz}$ ) were used in the latter study, concluding that all field components become sensitive to the formation conductivity and casing thickness only at frequencies higher than $2-4 \mathrm{~Hz}$. In the numerical and scale modeling study by Takacs and Hursan (1998), it was shown that using the steel casing of a deep borehole as an antenna has superior resolution for deep targets comparing 
to the electric source at the surface.

From the physical point of view, most of the electric currents travel long distances within a highly conducting casing along the wellbore, but, at the same time, a small amount of current leaks into the electrically conductive formation (Pardo et al. 2008). This effect depends on the frequency and conductivity of the formation layers. The casing has been described as a secondary source whose generated EM fields can be reproduced by a finite-length antenna of equivalent moment (Kong et al. 2009). The casing attenuation effect, i.e. the ratio of the dipole moment of the casing antenna to that of the source current, was found to be not far from unity for frequencies smaller than $1 \mathrm{~Hz}$ but then it rapidly decreased with an increase in frequency. Yang et al. (2009) investigated the possibility of enabling steel-cased wells as galvanic sources using simulations based on the integral -equation approach. Their results have shown that the rate of decay of electric current along the casing increases for decreasing casing conductivity or increasing background electric conductivity. Increase in frequency dramatically accelerates the rate of decay as well.

Cuevas (2012) analyzed the casing effect for the sources placed below the casing shoe using a 2D azimuthally symmetric code and found that it can be described by superimposing the electric field arising due to the vertical current induced in the pipe. Along the length of the casing, the amplitude of the field decreases exponentially away from the well with the spatial rate of decay depending on the conductivity of the surrounding formations. Cuevas (2014) studied the EM fields generated by a dipolar source placed inside an infinite casing and presented the approximate analytical solutions that illustrate the dependence of the fields on the various parameters of the model, thus providing a physical insight on the spatial distribution of the fields as well as on the physical behavior of the sources. Recently, the analysis of the casing effect has been extended in Cuevas (2016) to the channeling arising from the source-induced currents in pipes that extend horizontally in front of the dipolar antennas.

Computer simulations of EM phenomena in the presence of steel casings are much more challenging for conventional modeling tools. Thus, until recently, most of the modeling studies were based on one- and two-dimensional simulations. Some approximate methods also assumed the casing to be azimuthally symmetric and homogeneous. To be able to model complex scenarios, such as non-symmetric casings or casings composed of different materials with possibly different radii, one needs to include its representation directly in the model. The vast majority of three-dimensional (3D) methods used to calculate EM responses from steel-cased boreholes are based on the integral equations. However, most of the integral equation modeling techniques developed in the past century were found to fail for very high conductivity contrasts. 
Farquharson et al. (2006) provided a good overview of the limitations of the integral equation approach for models with large conductivity contrasts.

The most recent studies employ the finite-difference and finite-elements methods for modeling of the steel casing effect, usually with an approximate representation of the casing. Since the radius of the casing is very small in comparison with its vertical dimensions, in some applications, the steel casing can be represented as a solid tube. The tube, in its turn, can be further replaced with a distribution of vertical electric current dipoles that describe the channeling of current (Swidinsky et al. 2013). Tang et al. (2015) used a volume integral formulation to account for the finite thickness of the casing and combined this approach with a primary-secondary potential formulation for a general conductivity model using the finiteelement method. The feasibility of simulating realistic casing geometries has been demonstrated by Commer et al. (2015) where the finite- difference method has been applied for time-domain modeling studies of Earth models with anthropogenic metal structures. The casing has been completely included in the conductivity model and represented as a hollow cylinder on a structured mesh. Um et al. (2015) used a 3D finite-element time-domain algorithm to examine the use of a steel casing as a virtual electric source for sensing deep resistive and conductive targets. This study shows that the hollow casing can be adequately approximated with a rectangular prism, thus allowing to avoid a large number of tiny elements in the discretization and to reduce the computational cost. Finally, Börner et al. (2015) conducted a set of modeling studies using finite-element formulations on unstructured grids for CSEM, borehole transient EM, and the direct current resistivity method to define a set of optimal source/receiver configurations with respect to coverage, resolution, and detectability of the anomalous $\mathrm{CO}_{2}$ plume.

This article explores the sensitivity of a borehole-to-surface CSEM configuration with a deep electric dipole installed in the injection well and compares the modeling results with the baseline data set collected at the Hontomín CO2 storage site, Spain (Vilamajó et al. 2015). We begin with the description of the geophysical setup at Hontomín and the acquired data set in Sect. 2. In Sect. 3, we describe the modeling algorithm used to simulate the experimental configuration with an accurate representation of the injection well casing. In Sect. 4, we conduct a set of numerical simulations, compare them with the real field data and investigate the effect of the source distance to the base of the casing and variations in the resistivity model on CSEM data. Several post-injection scenarios are simulated in Sect. 5, and the time-lapse changes expected in CSEM data are determined. Finally, Sect. 6 contains concluding remarks and discussion. 


\section{The Hontomín $\mathrm{CO}_{2}$ storage site: geological and geophysical setup}

The Hontomín $\mathrm{CO}_{2}$ storage site is a pilot plant located in the southern part of the BasqueCantabrian Basin (Western Pyrenees, Spain). The Hontomín structure is a smooth Jurassic domed anticline with an overall extent of $3 \times 5 \mathrm{~km}^{2}$. Modern structural characterization studies include 3D reflection seismics (Alcalde et al. 2014), 2D (Ogaya et al. 2013) and 3D magnetotellurics (Ogaya et al. 2014). Ogaya et al. (2013) presented the 1D resistivity reference model and performed a 2D characterization of the geoelectrical structure. Ogaya et al. (2014) obtained the 3D geoelectrical baseline model after inverting 109 broadband sites. Well -log based petrophysical (Márquez and Jurado 2011) and hydrogeochemical (Buil et al. 2012) characterization studies of the Hontomín subsoil have been carried out, as well as a joint interpretation of the complementary geophysical data sets acquired (Ogaya et al. 2016).

One injection well (HI) and one monitoring well (HA) were drilled in 2013 as a part of the CO2 storage plant to a depth of $1570 \mathrm{~m}$ on the crest of the Jurassic dome. Both wells are equipped with electrical instrumentation in order to perform crosshole ERT monitoring and borehole-to-surface CSEM monitoring. At Hontomín, CO2 is sequestrated in a saline aquifer located approximately $1500 \mathrm{~m}$ deep. The primary reservoir has a minimum thickness of $100 \mathrm{~m}$ and is formed by a dolostone unit and a limestone unit. These units contain evaporates intercalations that may compartmentalize the reservoir. The seal formation comprises four blackshale levels interbedded in Lower Jurassic marls (Ogaya et al. 2014). From a geoelectrical point of view, the reservoir and the seal formations have a conductive response.

The feasibility of monitoring the $\mathrm{CO} 2$ sequestration at Hontomín was analyzed by Vilamajó et al. (2013) considering the specificities of the site. They simulated the expected changes in time-lapsed CSEM data and compared them directly with the EM noise in the area. The influence of the casings on the data was also considered by modeling solid vertical conductors at the positions of the injection and monitoring wells (three wells were planned to be drilled at that moment). This work determined the optimal experimental configurations (source/receiver positions and frequency range of emission) at the Hontomín site and indicated that it is crucial to understand the influence of the casings on the borehole-to-surface CSEM data.

The CSEM monitoring experiment was designed following the modeling results. The baseline campaign was carried out in 2014 (Vilamajó et al. 2015) and provided a wide data set of 
borehole-to-surface data with three different deep dipolar sources. Part of this data set is used in this work in order to compare the new modeling results with experimental data. The survey plan is shown in Fig. 1. The yellow dots show the location of the permanent electrodes used to measure the inline component of the surface electric field.

The first 1D resistivity model designed to simulate the EM behavior of the Hontomín structure was the stratified 11-layer model of Ogaya et al. (2013). This model was built using the resistivity log data from the $\mathrm{H} 2$ well located approximately $530 \mathrm{~m}$ away from the injection well. In this paper, we use a new $1 \mathrm{D}$ resistivity model in order to provide a more accurate description of the geoelectrical behavior of the structure. The new model has been derived using additional information from the resistivity logs of the injection well HI and monitoring well HA. The improved resistivity reference model (Fig. 2a) consists of 18 layers whose thicknesses (except the reservoir layer) vary from 20 to $80 \mathrm{~m}$ depending on the variations in the resistivity log data. The layer associated with the primary reservoir is located at a depth of $1353 \mathrm{~m}$ and is $117 \mathrm{~m}$ thick. The casing of the HI well, whos scheme is shown in Fig. 2b, extends down to the reservoir. This is the most conductive unit of the model $(10 \Omega \cdot \mathrm{m})$ and it contains the resistive $\mathrm{CO}_{2}$ plumes in the post-injections scenarios simulated in Sect. 5. More complex geoelectrical models were avoided in this study to focus on the effect of the steel casing.

\section{Modeling of the steel casing}

Three-dimensional EM modeling and inversion in the presence of highly conductive steel- cased wells is a nontrivial task. Extreme material contrasts and different spatial scales pose several numerical challenges to be addressed by the method. For the simulations, we develop a parallel three-dimensional finite-difference code based on the curl-curl electric field formulation that is similar to the method described in Puzyrev et al. (2015) with a few modifications. New features include support of parallel direct solvers, land CSEM configurations and updated automatic grid refinement to account for extreme cell aspect ratios. Three-dimensional finitedifference algorithms are well suited for parallel implementation on modern computer architectures and are dominantly used in the industry due to its convenient grid building and relatively simple use in inverse problems.

In order to verify the accuracy of the code, results obtained with the simulations for the 18-layer Hontomín model shown in Fig. 2a were compared to those obtained with a 1D reference code (Key 2009). The model setup was similar to the actual case without the surface that are 
found to be in good agreement. The errors in amplitudes are less than $1 \%$ for both short and long offsets. Differences in phases are negligible for the lowest $0.5 \mathrm{~Hz}$ frequency and reach about $0.8^{\circ}$ at offsets larger than $1 \mathrm{~km}$ for $32 \mathrm{~Hz}$.

A hollow steel casing of the HI well features a wall thickness of 1.5 inches and an outer radius of 8.5 inches. In this study, we neglect the effects of magnetic permeability of steel and set its relative permeability to 1 . Inside the casing, a circular hollow steel tube of an inner radius of 2.875 inches and an outer radius of 4.5 inches is present. Both the vertical casing and the tubing start at the ground surface $(\mathrm{z}=0 \mathrm{~m})$ and extend down to 1437 and $1456 \mathrm{~m}$, respectively (Fig. 2b).

The source is a vertical electric dipole (VED) consisting of two electrodes deployed at depths of 1500 and $1540 \mathrm{~m}$ in the HI well. We assume that there is no contact between the electrodes and the casing/tubing. Four square-wave signals with fundamental frequencies of 0.5 , 4, 32, and $128 \mathrm{~Hz}$ have been emitted. Receivers are stainless-steel electrodes permanently buried 1-1.5 m deep and distributed along two perpendicular profiles. We refer the reader to Vilamajó et al. (2015) for the description of data processing and experimental uncertainties.

In the numerical simulations, the steel casing is represented in a realistic way resulting in the smallest cell dimensions of $8 \mathrm{~mm}$. The casing should feature with many fine elements due to two main reasons: the huge conductivity contrast between the casing and the surrounding media, and the approximation of the curvilinear thin walls of the casing with a staircase finite-difference or a straight-sided finite-element model (Um et al. 2015). The cells gradually grow away from the well, and largest elements along the boundaries of the domain are several kilometers thick. The growth rate of the cells is chosen empirically to reduce the number of unknowns in the problem and at the same time keep the accuracy of the numerical scheme within reasonable bounds. Fig.4 shows plane XY views of the central part of the discretization grids. The most accurate representation of the casing and tubing (Fig. 4a) has been used in the subsequent simulations. Two approximations (Fig. 4b, c) have been used only to study the accuracy loss and computational gain of using coarse casing representations. Using a full $3 \mathrm{D}$ representation of the well allows us to consider the casing of varying geometry, thickness and conductivity (that might arise from corrosion effects). Such benefits are, in particular, of great importance for deviated wells that are commonly used in the industry nowadays.

The electrical conductivity of steel varies from $1.410^{6} \mathrm{~S} / \mathrm{m}$ (stainless steel) to $6.9910^{6}$ $\mathrm{S} / \mathrm{m}$ (carbon steel). In this study, we consider a value of $5.010^{6} \mathrm{~S} / \mathrm{m}$ for the casing conductivity, whereas the conductivities of the structure formation at Hontomín range from 0.001 to $0.1 \mathrm{~S} / \mathrm{m}$. Thus, the difference in material properties along the casing is of $8-9$ orders of magnitude. The 
conductivity of the air is set to $10^{-6} \mathrm{~S} / \mathrm{m}$. Higher values of air conductivity were found to cause small errors in measurements at the surface. Conductivity contrast between the casing and the air layer exceeds 12 orders of magnitude.

The use of grids with large aspect ratios between elements and huge materials' contrasts leads to ill-conditioned matrices and introduces computational difficulties for iterative solvers. Several iterative methods from the PETSc library (Balay et al. 2016), as well as some in-house developments (Puzyrev and Cela 2015) have been tried to solve the largest model, but failed to converge to the desired tolerance of $10^{-8}$. Such problems are reliably solvable using direct sparse linear solvers. The key challenge in using a direct method is to keep within the memory limit and to maintain computational tractability, especially when integrated with an inversion framework. In this study, we have employed the shared- memory solver PARDISO (Schenk and Gärtner 2004) which is based on memory-efficient supernodal techniques and thus requires relatively lower amounts of memory for the matrix factorization compared to some other direct solvers (Puzyrev et al. 2016). We should also note that the extension of the method to unstructured or semi-structured grids using the finite-element or the finite-volume methods would allow for large computational savings. The effect of a more accurate casing representation with locally refined tetrahedra (or even curvilinear elements) should not be large for this type of problem; however, it can be much more important for the applications when the EM response is measured inside or close to the borehole.

\section{Numerical results and comparison with the real data}

Vilamajo' et al. (2015) presented the CSEM monitoring baseline experiment and the processing approach. They showed that the borehole-to-surface experimental data were lar- gely influenced by the casing and tubing infrastructures, providing an amplitude of the surface electric field more than two orders of magnitude larger than the estimated result for a stratified subsoil model without casings. In order to quantify the current induction along the casing, they used the so-called transmission-line approximation (Kong et al. 2009) that describes for low frequencies the current flowing along a steel casing in terms of the casing dimension and the resistivity contrast with the embedding medium. They extended the use of the equation to each layer of the $1 \mathrm{D}$ reference model showing a good agreement between the experimental data and the assumption simulated. Nevertheless, when trying to reproduce the experimental data by modeling a coarse casing, they reported some difficulties attributed to the unrealistic simulation 
of the casing. Realistic modeling studies are needed to better understand real data and to identify and characterize different factors affecting it, for instance: the effect of steel-cased wells and other infrastructure, the background resistivity of the reservoir, the exact position of the deep sources, etc. In this section, we report the results of a set of numerical simulations for the Hontomín CSEM experiment and compare them with the real field data.

Fig. 5 shows the electric field amplitude in the vertical plane $y=0$ when the realistic representation of the casing is included in the model. As a source we consider a vertical electrical dipole (VED) located below the HI injection well at a depth of $1500 \mathrm{~m}$. We can see a large amount of current channeling along its casing toward the surface. For the 4-Hz frequency, almost no decay in the amplitude along the casing is observed. For the highest frequency of $128 \mathrm{~Hz}$, the EM signal attenuates more. The casing serves as a channel through which electrical currents flow to the surface and produce large perturbations in the measured surface electric field. In the nearcasing zone and up to several hundred meters away, the amplitude of the horizontal electric field is $2-3$ orders of magnitude larger than the simulation results without the casing.

In order to see the effect of the steel casing on the signal amplitude at the surface, in Fig. 6 we compare the experimental amplitude of the inline electric field at the surface with the modeling results obtained with a layered background without the casing (red dashed line) and with the realistic simulation of the casing (blue line). The presence of the casing results in a significant amplification of the EM signal at the surface. The casing effect dominates at all receivers and is especially strong at short offsets (up to several hundred meters from the well). The effect decreases with increasing distance from the well, however, it is still strong even at the largest offsets of $1500 \mathrm{~m}$. The impact of the deep steel-cased well on the land CSEM data is stronger than in the marine borehole-to-surface scenario described by Cuevas (2012) where the casing effect of a $\sim 750 \mathrm{~m}$ deep borehole dominated the response at close distances $(<500 \mathrm{~m})$, while at larger offsets the response of the formation dominated the distorting casing fields.

As expected, we can qualitatively reproduce the data collected in the experiment. However, the modeled surface response is approximately 0.5 orders of magnitude weaker than the field data for all four base frequencies. These differences can be explained either by a different position of the vertical source or by an inaccurate conductivity model, or a combination of the two. As will be shown below, the source position (i.e. the distance to the casing) is the key factor determining the signal's strength. The following two figures analyze the plausibility of these two hypotheses.

Fig. 7 illustrates dependence of the amplitudes of the surface electric field on the depth of the vertical source. It can be easily noted that when the VED source is located in the vicinity of 
the well's tubing (1460 $\mathrm{m}$ deep), the surface responses are much stronger than for the sources located just 20 and 40 meters deeper. Locating vertical electric source closer to the casing results in an increase in the amplitude of the electric field at the surface and can improve the signal-tonoise ratio. We should note that, for all four frequencies, the amplitudes of the real data are located between the curves for the 1460- and 1480-m sources. The real data would be a good match to the simulation results when the VED is located approximately $1470 \mathrm{~m}$ deep.

The other hypothesis is an inaccurate characterization of the geoelectrical structure. In order to investigate the influence of a conductivity model, we simulate a limit scenario when all the layers above the seal/reservoir layer are substituted with a resistive $(1000 \Omega \cdot \mathrm{m})$ medium. As can be seen from Fig. 8, for some frequencies the limit scenario provides amplitude responses of the same order of magnitude as the experimental data. However, the behavior of the amplitude of the electric field is highly dependent on the frequency employed. The simulation results for 0.5 , 4 and $32 \mathrm{~Hz}$ reproduce the order of magnitude of the experimental data, whereas for the $128 \mathrm{~Hz}$ signal, the synthetic data have a larger amplitude. These results show that the differences reported in Fig. 6 between the experimental data and the modeling results (which are almost independent of frequency) cannot be explained exclusively by an inaccurate conductivity model, especially given the fact that the latter relies on well log data.

We can also note that for the three lowest frequencies shown in Fig. 8, the signal strength at the surface is almost independent of frequency. This behavior is typical for instruments working in a low induction number (LIN) mode. The dimensionless induction number is defined as (Zonge and Hughes 1991)

$$
B=\frac{r}{\delta}
$$

i.e. the ratio of the source-receiver separation $r$ divided by the skin depth $\delta$. The electromagnetic skin depth for a given conductivity $\sigma$ and angular frequency $\omega$ is given as

$$
\delta=\sqrt{\frac{2}{\sigma \omega \mu_{0}}} .
$$

The near-field zone of the dipole is characterized by low induction numbers $\mathrm{B}<<1$. In this zone, the electric field is directly proportional to resistivity and is independent of frequency (the magnetic field is independent of both). For the maximum source-receiver separation in the Hontomín model, the induction numbers of the first three frequencies under consideration in a resistive $1000 \Omega \cdot \mathrm{m}$ medium are approximately $0.094,0.27$, and 0.75 . The little dependence on the modeling frequency that we observe in Fig. 8 is typical for the LIN regime. The maximum 
induction number for $128 \mathrm{~Hz}$ is $\sim 1.51$ that corresponds to the near-field/far-field transition zone (Zonge and Hughes 1991)..

A realistic representation of the casing that we used in the previous experiments is often considered impractical due to its high computational cost. For example, the finest discretization of the casing shown in Fig. 4a results in a linear system with more than 6 millions of complex unknowns. Sparse systems of this size are solvable with direct solvers (Puzyrev et al. 2016), but they require a shared-memory system with several hundred gigabytes of memory for matrix factorization with PARDISO or the use of distributed- memory direct solvers on distributedmemory computing platforms. An alternative way to model the steel casing effect is to consider some approximations of the casing that allow alleviating the high computational cost. To better understand the discretization rules of the casing and examine the accuracy of different approximations, in Fig. 9 we show the results of the simulations using the same setup, but with two casing approximations shown in Fig. $4 \mathrm{~b}$, c. The first one is built on the same grid as the original hollow casing model, but the casing is represented as a solid tube. In the second approximation, the solid casing is discretized on a much coarser grid resulting in a system with $\sim 3.5$ millions of unknowns. By not discretizing the interior of the casing, we are able not only to significantly reduce the number of unknowns in the linear system but also to improve the matrix condition number. The run time on a system equipped with two 12-core Intel Xeon E5-2690 v3 Haswell processors was about $3 \mathrm{~h}$ for the fine-grid problem and $1 \mathrm{~h}$ for the coarse-grid case. The same value of steel conductivity is used in both approximations. Alternatively, the principle of conductivity-thickness product of the tube (Swidinsky et al. 2013) can be employed. As can be seen from Fig. 9, the surface responses over the hollow and solid casings are practically the same. For the coarse-grid model, the largest errors of about 2 percent in amplitude and $0.6^{\circ}$ in phase are observed at short offsets and then quickly decrease with the distance.

\section{Feasibility of $\mathrm{CO}_{2}$ monitoring near steel-cased wells}

In this section, we simulate post-injection scenarios and determine the time-lapse changes expected in CSEM responses at the surface. Two scenarios of post- $\mathrm{CO}_{2}$ injection are considered to address key practical questions about the behavior of the EM fields distorted by the casing effect

At Hontomín, the reservoir is located in a deep saline aquifer characterized by highly conductive brine and low clay content (Ogaya et al. 2013). In this situation, Archie's equation 
can be used to estimate the resistivity change due to the $\mathrm{CO} 2$ injection. Assuming that only two fluid phases (the brine and the injected $\mathrm{CO} 2$ ) are present in the post-injection reservoir formation and that no dissolution or precipitation happens, the pre-injection and post-injection resistivities of the formations can be related as

$$
\frac{\rho}{\rho_{0}}=(1-S)^{-n}
$$

where $S$ is the $\mathrm{CO}_{2}$ saturation factor and $n$ is the saturation exponent. In this case, a value of $n$ equal to 2 is assumed (clean sand). A homogenous saturation of $50 \%$ results in a post-injection to pre-injection resistivity contrast of 4 . Since Hontomín is a non-commercial project, the injection will not exceed 20,000 tonnes. Considering the pressure and temperature conditions at the reservoir depth, this volume and the maximum injection planned, we simulate a $\mathrm{CO}_{2}$ volume of $185 \times 185 \times 14 \mathrm{~m}$. The bottom of this plume is located at $1470 \mathrm{~m}$ and its top touches the tubing at $1456 \mathrm{~m}$. For comparison, we also perform modeling studies for a large industrial-scale $\mathrm{CO}_{2}$ plume with the dimensions of $472 \times 472 \times 105 \mathrm{~m}$ that represents a hypothetical injection of 1 Mton. The VED source is located at a depth of $1480 \mathrm{~m}, 10 \mathrm{~m}$ below the target in a resistive 122 $\Omega \cdot \mathrm{m}$ basement of the model.

Fig. 10 shows the ratios of the amplitudes of the horizontal electric field for different positions of the small $\mathrm{CO} 2$ plume. The results of the simulations confirm that the borehole- tosurface EM tools are sensitive to resistive targets located not too far away from the source in the presence of the steel-cased wells. Amplitudes for the post-injection scenario are 8-12\% larger than for the pre-injection case; the difference is stronger for higher frequencies. The phase changes are relatively small and do not exceed $2^{\circ}$ even for the highest frequency and hence are not shown here. The key characteristic is the thickness of the plume near the vertical axis of the well. Additional simulations show that very thin resistive targets $(5 \mathrm{~m}$ thick or less) result in a relative change in the amplitudes of the surface field smaller than 3-5\% that can be easily hidden in the signal noise.

Differences in the amplitudes of the horizontal electric field for the large $\mathrm{CO} 2$ plume are shown in Fig. 11 for different source positions. In this case, the changes in surface responses are much stronger. In particular, for the $128-\mathrm{Hz}$ frequency they reach $40 \%$ for the sources located below the plume and $93 \%$ for the source inside it (1460 $\mathrm{m}$ deep). Differences in phases are also much larger and reach $20^{\circ}$ for the highest $128-\mathrm{Hz}$ frequency. All frequencies provide useful information about the target; however, for the sources located below it, relative changes for frequencies below $10 \mathrm{~Hz}$ are smaller than for higher ones. 
Studying the surface responses for an industrial-scale $\mathrm{CO}_{2}$ monitoring scenario provides valuable insights into the potential of using steel casing of the wells to better characterize deep targets through the amplification of electric source current. Volume and resistivity changes lead to observable differences in EM responses at the surface for both non- commercial and industrials-scale plumes.

\section{Discussion and conclusions}

In various CSEM applications, electric sources are located near the steel casing of the boreholes resulting in large electric currents diffusing through them and strongly influencing the surface measurements. This effect has to be taken into consideration when developing electromagnetic modeling and inversion tools and interpreting land-based CSEM experimental data. While some approximate schemes utilize the symmetry of the casing and can efficiently model simple geometric structures, full 3D simulations are needed for complex geological scenarios, arbitrary trajectory wells or when heterogeneous conductivities are present in the casing. A realistic 3D modeling with an accurate representation of a hollow steel casing is numerically challenging but feasible on modern desktop computers and small clusters, as shown in this study.

Given the extreme grid aspect ratios and conductivity contrasts in the models, we employ parallel direct solvers to deal with the highly ill-conditioned resulting systems. Recent progress in sparse direct solvers and parallel computing allows us to apply these solvers efficiently even to large 3D problems. Approximations of the casing with a solid cylinder or prism can be used to reduce the total number of cells required to represent the casing and hence the computational burden of modeling and inversion. Good agreement between the responses for the realistic and approximate casing models demonstrates the feasibility of this approach. The relative differences in surface responses for three casing representations considered in this study are bounded within about $2 \%$ in amplitudes and $0.6^{\circ}$ in phases. The use of coarse-grid solid approximations makes it practically possible to consider multiple cased wells or other steel infrastructure in inverse modeling applications. Three-dimensional modeling algorithms based on unstructured grids would make the simulations even more accurate, faster, less memory demanding and allow for support of arbitrary well trajectories.

Realistic 3D modeling of the casing effect on the borehole-to-surface Hontomín setup is able to produce results that are quantitatively similar to the real experimental data. Two 
hypotheses have been proposed and tested to reproduce the experimental data: a lack of knowledge of the exact depth of the source electrodes and an inaccurate characterization of the geoelectrical response. Both of them are able to quantitatively reproduce the experimental data. A combination of these hypotheses may explain the discrepancy between the data and the simulation results.

The casing greatly amplifies the signal and enlarges the signal-to-noise ratio, making the surface measurements more sensitive to conductivity changes near the bottom of the well. In noisy areas, this may greatly increase the efficiency of $\mathrm{CO}_{2}$ monitoring with a borehole- tosurface configuration. This is similar to the results of other studies where the conductive casing is used for better characterization of deep zones using surface-to-surface and surface-to-borehole configurations.

In the $\mathrm{CO}_{2}$ injection scenarios, we simulate the time-lapse changes expected in CSEM responses at the surface. All frequencies from the range used in this study provide useful information about the target migration. The differences in the field amplitudes between the postand pre-injection scenarios increase with increase in frequency. It is shown that the changes in time-lapsed borehole-to-surface CSEM data acquired under the influence of steel casings are sufficiently large to be detected in a real experiment. Therefore, the CSEM monitoring at the Hontomín storage site will be able to detect the resistivity changes at the reservoir depth.

\section{ACKNOWLEDGMENTS}

The authors would like to thank the Editor-in-Chief, Michael J. Rycroft, Colin Farquharson and one anonymous reviewer for their suggestions that helped to improve the presentation of this paper. This work was supported by computational resources provided by the Pawsey Supercomputing Centre with funding from the Australian Government and the Government of Western Australia. The authors would like to acknowledge the PARDISO developers for providing an academic license. The first author also acknowledges support from the RISE Horizon 2020 European Project GEAGAM (644202). EV, PQ, JL and AM thank Ministerio de Economía y Competitividad and EU Feder Funds through grant CGL2014-54118C2-1-R. Funding for this Project has been partially provided by the Spanish Ministry of Industry, Tourism and Trade, through the CIUDEN-Fundació Bosch i Gimpera agreement (ALM-09-010) Development and Adaptation of Electromagnetic techniques: control and monitoring of storage sites and in collaboration with the French EM-Hontomin ANR project. 


\section{REFERENCES}

1. Alcalde J, Marzán I, Saura E, Martí D, Ayarza P, Juhlin C, Pérez-Estaún A, Carbonell R (2014) 3D geological characterization of the Hontomín CO2 storage site, Spain: Multidisciplinary approach from seismic, well-log and regional data. Tectonophysics 627:6-25

2. Augustin AM, Kennedy WD, Morrison HF, Lee KH (1989) A theoretical study of surface-toborehole electromagnetic logging in cased holes. Geophysics 54:90-99

3. Balay S, Abhyankar S, Adams M, Brown J, Brune P, Buschelman K, Dalcin L, Eijkhout V, Gropp W, Karpeyev D, Kaushik D, Knepley M, Curfman McInnes L, Rupp K, Smith B, Zampini S, Zhang H, Zhang H (2016) PETSc Users Manual, ANL-95/11 - Revision 3.7. http://www.mcs.anl.gov/petsc

4. Bhuyian AH, Landrø M, Johansen SE (2012) 3D CSEM modeling and time-lapse sensitivity analysis for subsurface CO2 storage. Geophysics 77(5):E343-E355

5. Börner JH, Wang F, Weißflog J, Bär M, Görz I, Spitzer K (2015) Multi-method virtual electromagnetic experiments for developing suitable monitoring designs: A fictitious $\mathrm{CO} 2$ sequestration scenario in Northern Germany. Geophys Prospect 63(6):1430-1449

6. Buil B, Gomez P, Pena J, Garralon A, Galarza C, Duran JM, Dominguez R, Escribano, A, Turrero MJ, Robredo LM, Sanchez L (2012) Caracterizacion y monitorizacion hidrogeoquimica de los acuíferos superiores a la formacion almacenamiento de CO2 (Hontomin, Burgos) y actualizacion de la caracterizacion de aguas superficiales. Technical report CIEMAT/DMA/2G010/1/2012

7. Colombo D, McNeice GW (2013) Quantifying surface-to-reservoir electromagnetics for waterflood monitoring in a Saudi Arabian carbonate reservoir. Geophysics 78(6):E281-E297

8. Commer M, Hoversten GM, Um ES (2015) Transient-electromagnetic finite-difference timedomain earth modeling over steel infrastructure. Geophysics 80(2):E147-E162

9. Constable S (2010) Ten years of marine CSEM for hydrocarbon exploration. Geophysics 75(5):75A67-75A 81

10. Cuevas N (2012) Casing effect in borehole-surface (surface-borehole) EM fields. In 74th EAGE Conference and Exhibition incorporating EUROPEC 2012, EAGE

11. Cuevas N (2014) Analytical solutions of EM fields due to a dipolar source inside an infinite casing.Geophysics 79(5):E231-E241

12. Cuevas N (2016) Field distortion due to surface pipes in surface to borehole electromagnetic. In: 78th EAGE conference and exhibition, EAGE

13. Davydycheva S, Rykhlinski N (2011) Focused-source electromagnetic survey versus standard CSEM: 3D modeling in complex geometries. Geophysics 76(1):F27-F41 
14. Escalas M, Queralt P, Ledo J, Marcuello A (2013) Polarisation analysis of magnetotelluric time series using a wavelet-based scheme: a method for detection and characterisation of cultural noise sources. Phys Earth Planet Inter 218:31-50

15. Farquharson CG, Duckworth K, Oldenburg DW (2006) Comparison of integral equation and physical scale modeling of the electromagnetic responses of models with large conductivity contrasts. Geophysics 71(4):G169-G177

16. Grayver AV, Streich R, Ritter O (2014) 3D inversion and resolution analysis of land-based CSEM data from the Ketzin CO 2 storage formation. Geophysics 79(2):E101-E114

17. Hoversten GM, Commer M, Schwarzbach C, Haber E (2016) Multi-physics inversion for reservoir moni- toring. In: 78th EAGE conference and exhibition workshops, EAGE

18. Kang S, Seol SJ, Byun J (2012) A feasibility study of CO 2 sequestration monitoring using the mCSEM method at a deep brine aquifer in a shallow sea. Geophysics 77(2):E117-E126

19. Kaufman A (1990) The electrical field in a borehole with casing. Geophysics 55:29-38

20. Key K (2009) 1D inversion of multicomponent, multifrequency marine CSEM data: Methodology and synthetic studies for resolving thin resistive layers. Geophysics 74(2):F9-F20

21. Kong FN, Roth F, Olsen PA, Stalheim SO (2009) Casing effects in the sea-to-borehole electromagnetic method. Geophysics 74(5):F77-F87

22. Le CV, Harris BD, Pethick AM, Takougang EMT, Howe B (2016) Semiautomatic and automatic cooperative inversion of seismic and magnetotelluric data. Surv Geophys 37(5):845-896

23. MacGregor L (2012) Integrating seismic, CSEM and well log data for reservoir characterization. The Leading Edge 31(3):258-265

24. Márquez M, Jurado MJ (2011) Petrophysical characterization of a CO2 storage reservoir using well logs. Geophys Res Abstr Vol. 13

25. Muñoz G (2014) Exploring for geothermal resources with electromagnetic methods. Surv Geophys 35(1):101-122

26. Ogaya X, Ledo J, Queralt P, Marcuello Á, Quintà A (2013) First geoelectrical image of the subsurface of the Hontomín site (Spain) for $\mathrm{CO} 2$ geological storage: a magnetotelluric 2D characterization. Int J Greenh Gas Con 13:168-179

27. Ogaya X, Queralt P, Ledo J, Marcuello Á, Jones AG (2014) Geoelectrical baseline model of the subsurface of the Hontomín site (Spain) for CO 2 geological storage in a deep saline aquifer: A 3D magnetotelluric characterisation. Int J Greenh Gas Con 27:120-138

28. Ogaya X, Alcalde J, Marzán I, Ledo J, Queralt P, Marcuello A, Martí D, Saura E, Carbonell R, Benjumea B (2016) Joint interpretation of magnetotelluric, seismic and well-log data in Hontomín (Spain). Solid Earth 7:943-958

29. Pardo D, Calo VM, Torres-Verdín C, Nam MJ (2008) Fourier series expansion in a nonorthogonal system of coordinates for the simulation of 3D-DC borehole resistivity measurements. Comput Methods Appl.Mech Eng 197(21):1906-1925 
30. Puzyrev V, Cela JM (2015) A review of block Krylov subspace methods for multisource electromagnetic modelling. Geophys J Int 202:1241-1252

31. Puzyrev V, Gutierrez N, Rodriguez JE, Hanzich M, de la Puente J (2015) Electromagnetic modeling using a massively parallel software framework. In 77th EAGE Conference and Exhibition, EAGE

32. Puzyrev V, Koric S, Wilkin S (2016) Evaluation of parallel direct sparse linear solvers in electromagnetic geophysical problems. Comput Geosci 89:79-87

33. Schenk O, Gärtner K (2004) Solving unsymmetric sparse systems of linear equations with PARDISO. Fut. Gen. Comput Syst 20:475-487

34. Schenkel CJ, Morrison HF (1994) Electrical resistivity measurement through metal casing. Geophysics 59(7):1072-1082

35. Schwalenberg K, Willoughby E, Mir R, Edwards RN (2005) Marine gas hydrate electromagnetic signatures in Cascadia and their correlation with seismic blank zones. First Break 23(4):57-63

36. Strack KM (2014) Future directions of electromagnetic methods for hydrocarbon applications. Surv Geophys 35(1):157-177

37. Streich R (2016) Controlled-source electromagnetic approaches for hydrocarbon exploration and monitoring on land. Surv Geophys 37(1):47-80

38. Streich R, Becken M, Ritter O (2013) Robust processing of noisy land-based controlled-source electro- magnetic data. Geophysics 78(5):E237-E247

39. Swidinsky A, Edwards RN, Jegen M (2013) The marine controlled source electromagnetic response of a steel borehole casing: Applications for the NEPTUNE Canada gas hydrate observatory. Geophys Prospect 61(4):842-856

40. Takacs E, Hursan G (1998) A nonconventional geoelectric method using EM field generated by steel-casing excitation. In 68th SEG Annual International Meeting Expanded Abstracts: pp 452455

41. Tang W, Li Y, Swidinsky A, Liu J (2015) Three-_dimensional controlled--source electromagnetic modelling with a well casing as a grounded source: a hybrid method of moments and finite element scheme. Geophys Prospect 63(6):1491-1507

42. Tietze K, Ritter O, Veeken P (2015) Controlled-source electromagnetic monitoring of reservoir oil saturation using a novel borehole-to-surface configuration. Geophys Prospect 63(6):14681490

43. Um ES, Commer M, Newman GA, Hoversten GM (2015) Finite element modelling of transient electromagnetic fields near steel-cased wells. Geophys J Int 202(2):901-913

44. Vilamajó E, Queralt P, Ledo J, Marcuello A (2013) Feasibility of monitoring the Hontomín (Burgos, Spain) CO2 storage site using a deep EM source. Surv Geophys 34(4):441-461

45. Vilamajó E, Rondeleux B, Queralt P, Marcuello A, Ledo J (2015) A land controlled-_source electromagnetic experiment using a deep vertical electric dipole: experimental settings, 
processing, and first data interpretation. Geophys Prospect 63(6):1527-1540

46. Wirianto M, Mulder WA, Slob EC (2010) A feasibility study of land CSEM reservoir monitoring in a complex 3-D model. Geophys J Int 181(2):741-755

47. Wu X, Habashy T (1994) Influence of steel casing on EM signals. Geophysics 59:378-390

48. Yang W, Torres-Verdín C, Hou J, Zhang Z (2009) 1D subsurface electromagnetic fields excited by energized steel casing. Geophysics 74(4):E159-E180

49. Zhdanov MS, Endo M, Black N, Spangler L, Fairweather S, Hibbs A, Eiskamp GA, Will R (2013) Electromagnetic monitoring of CO2 sequestration in deep reservoirs. First Break 31(2):71-78

50. Zonge KL, Hughes LJ (1991) Controlled source audiofrequency magnetotellurics. In: Nabighian MN (ed) Electromagnetic Methods in Applied Geophysics, Vol. 2, Applications, Society of Exploration Geophysicist, Tulsa 


\section{Figure captions.}

Fig. 1 General view of the Hontomín $\mathrm{CO}_{2}$ storage site. The red dots show the location of the newest HI and HA wells. The yellow dots indicate the permanent electrodes used to measure the inline component of the surface electric field.

Fig. 2 (a) Hontomín layered resistivity models: original 11-layer resistivity model (red dotted line) and improved 18-layer model (blue line). (b) Scheme of the HI well casing and tubing.

Fig. 3 Comparison of the amplitudes (left) and phases (right) of the horizontal surface electric field for the 18-layer Hontomín model without the casing. Frequencies of $0.5 \mathrm{~Hz}$ (top) and $32 \mathrm{~Hz}$ (bottom) are considered. Results of the 3D simulations are marked with blue crosses and $1 \mathrm{D}$ analytical results are shown by red lines.

Fig. 4 Plane XY view of the discretization grids near the casing. (a) The most accurate representation. (b) The solid casing approximation using the same grid as in the previous case. (c) The solid casing approximation on a coarse grid.

Fig. 5 The electric field amplitude in the central vertical plane $(y=0)$ for the case when the casing is included in the model. Results for the frequencies of $4 \mathrm{~Hz}$ (top) and $128 \mathrm{~Hz}$ (bottom) are shown.

Fig. 6 Amplitudes of the horizontal surface electric field obtained considering (blue line) or ignoring (red dotted line) the casing versus measured at the inline-oriented surface receivers along Profile 1 (red squares) and Profile 2 (blue circles). All four fundamental frequencies of 0.5 $\mathrm{Hz}$ (top left), $4 \mathrm{~Hz}$ (top right), $32 \mathrm{~Hz}$ (bottom left), and $128 \mathrm{~Hz}$ (bottom right) are shown.

Fig. 7 Amplitudes of the horizontal surface electric field for three different source depths (see the sketch at the bottom of the figure) for the frequencies of $0.5 \mathrm{~Hz}$ (top left), $4 \mathrm{~Hz}$ (top right), $32 \mathrm{~Hz}$ (bottom left), and $128 \mathrm{~Hz}$ (bottom right).

Fig. 8 Amplitudes of the horizontal surface electric field for the 18-layer resistivity model (blue line) versus the response for a homogeneous resistive $1000 \Omega \cdot \mathrm{m}$ medium above the 
seal/reservoir layer (red dotted line). The same frequencies of $0.5 \mathrm{~Hz}$ (top left), $4 \mathrm{~Hz}$ (top right), $32 \mathrm{~Hz}$ (bottom left), and $128 \mathrm{~Hz}$ (bottom right) are considered.

Fig. 9 Comparison of the surface electric field for the casing approximations shown in Fig. 4. (a) Amplitudes of the horizontal electric field. (b) Ratios of the amplitudes. (c) Phases of the horizontal electric field. (d) Differences in the phases.

Fig. 10 Ratios of the electric field amplitudes for the small 20 kton $\mathrm{CO}_{2}$ plume for the fundamental frequencies of $0.5 \mathrm{~Hz}$ (top left), $4 \mathrm{~Hz}$ (top right), $32 \mathrm{~Hz}$ (bottom left), and $128 \mathrm{~Hz}$ (bottom right). Four different positions of the plume (see the sketch at the bottom of the figure) represent its migration in horizontal direction.

Fig. 11 Ratios of the electric field amplitudes for the large $1 \mathrm{Mton} \mathrm{CO}_{2}$ plume for three different source depths (see the sketch at the bottom of the figure). The same frequencies of 0.5 $\mathrm{Hz}$ (top left), $4 \mathrm{~Hz}$ (top right), $32 \mathrm{~Hz}$ (bottom left), and $128 \mathrm{~Hz}$ (bottom right) are considered. 


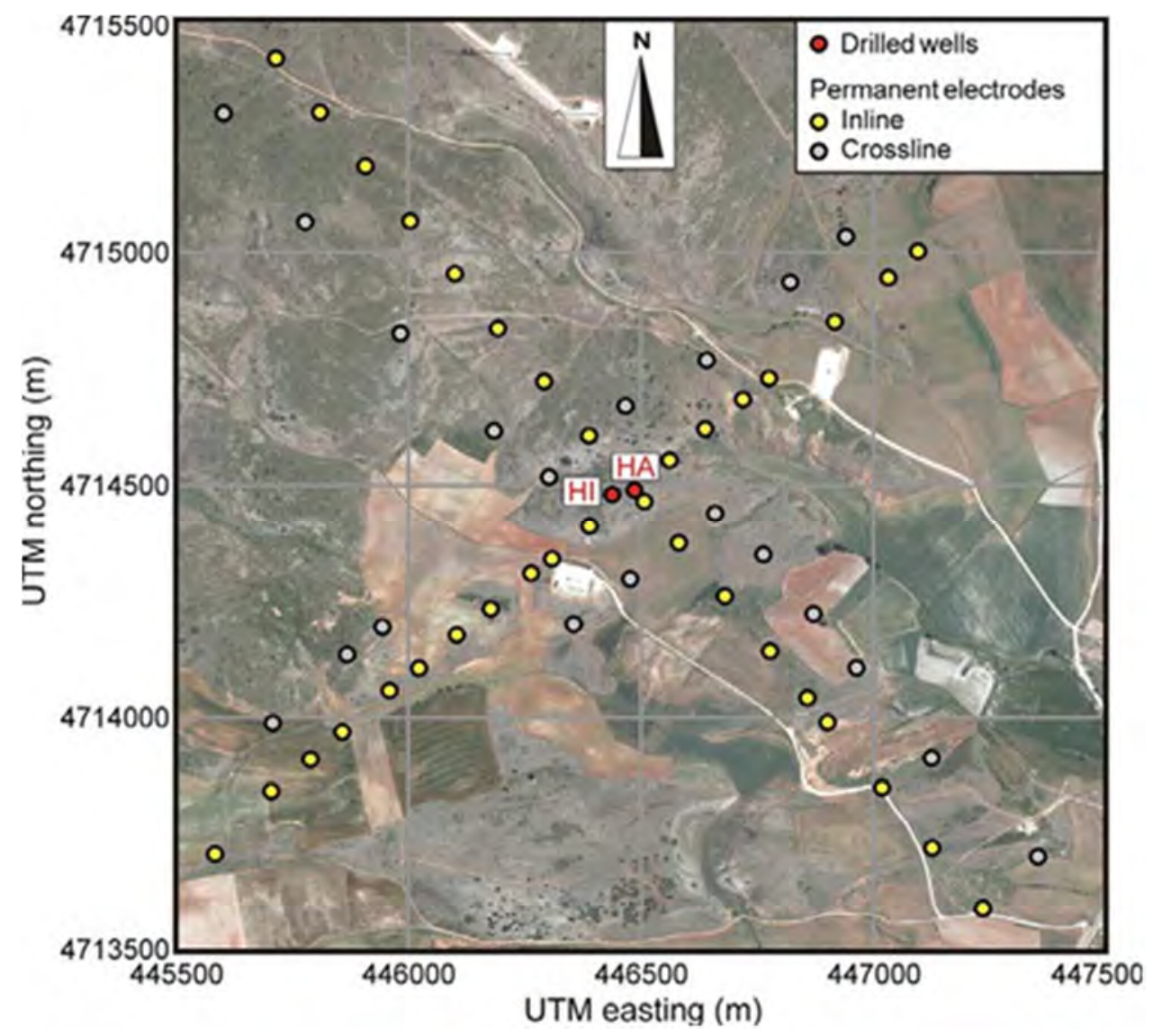

Figure 1 


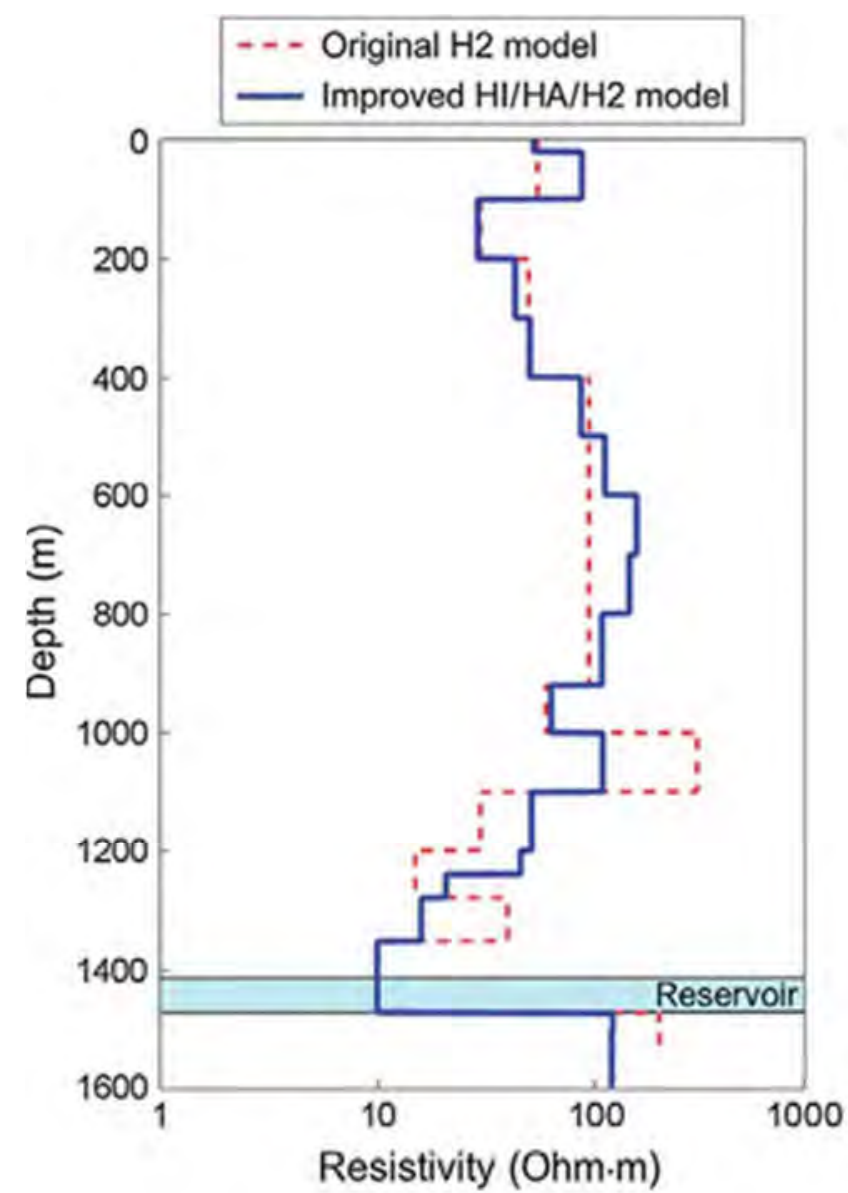

(a)

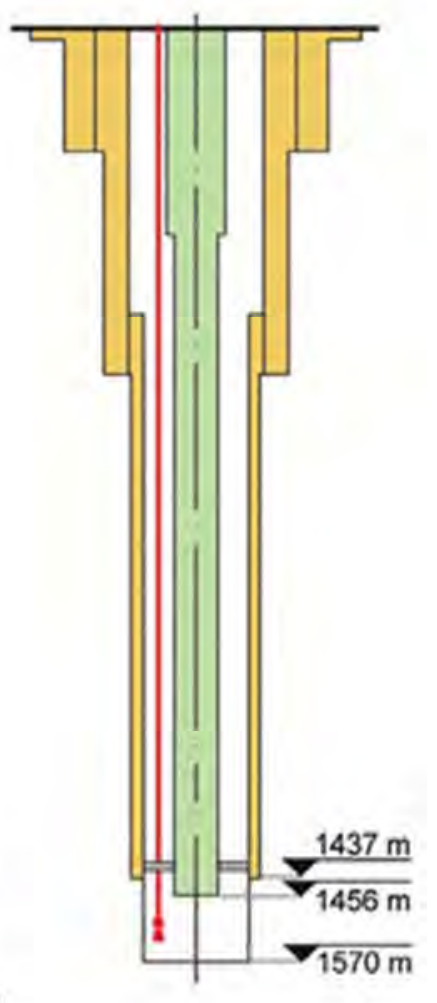

(b)

Figure 2 

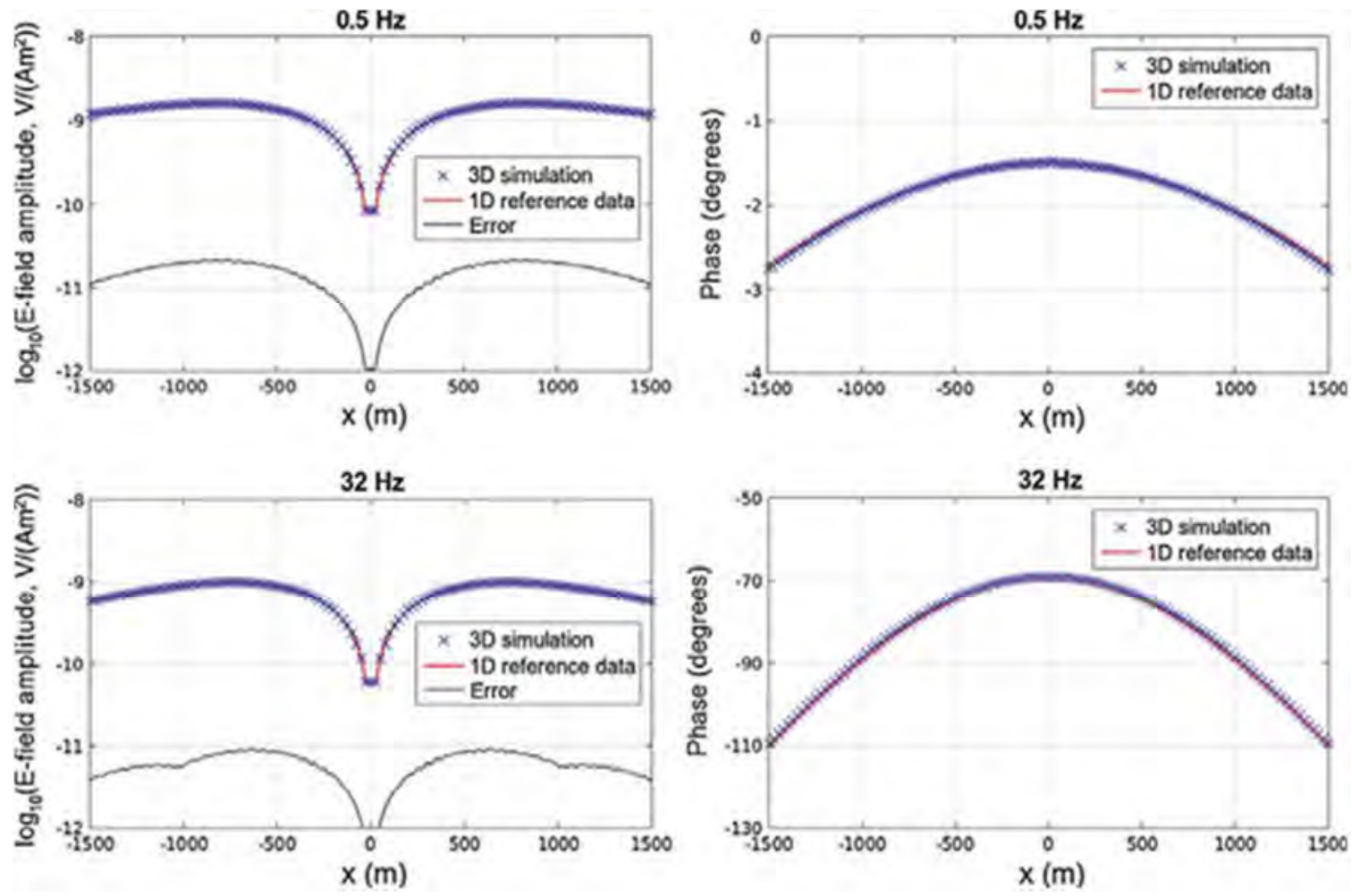

Figure 3 


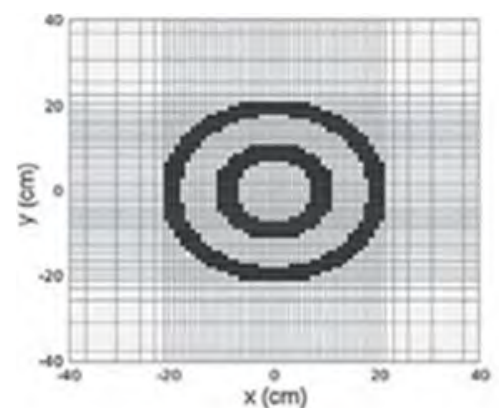

(a)

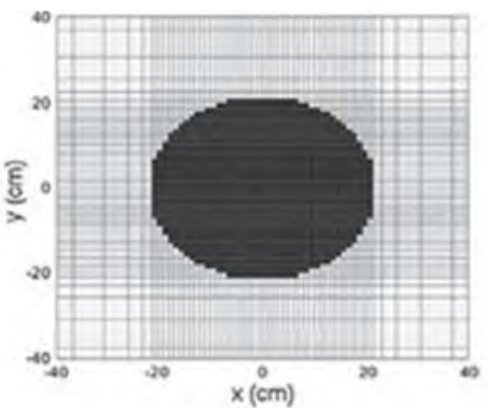

(b)

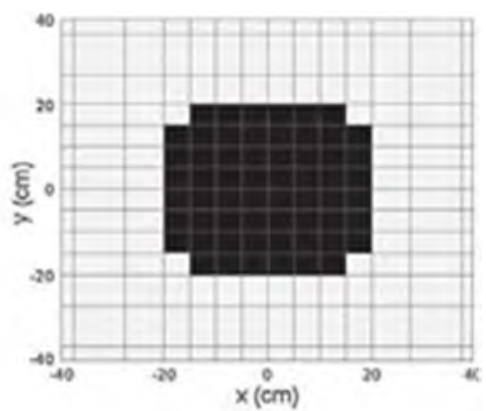

(c)

Figure 4 


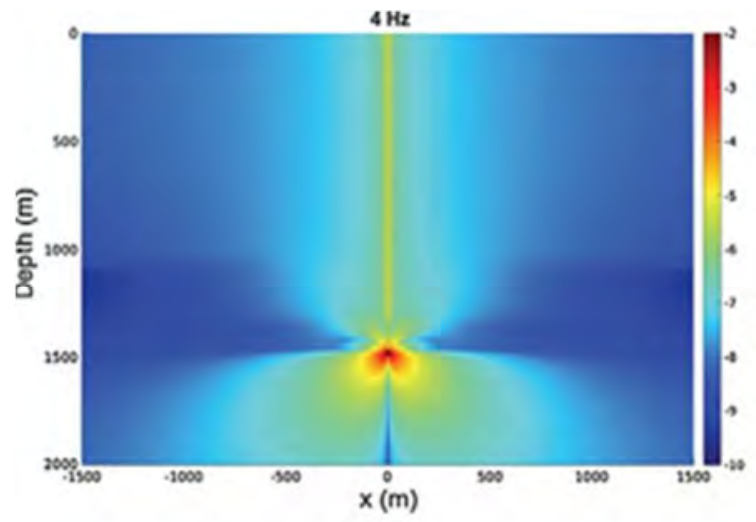

(a)

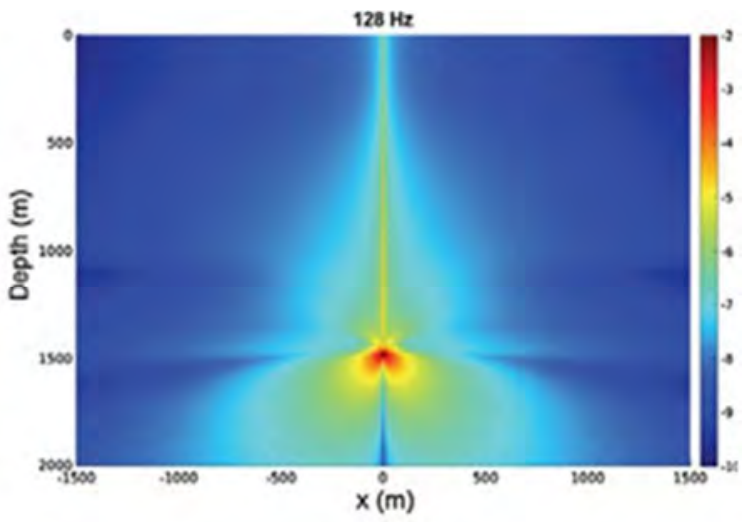

(b)

Figure 5 

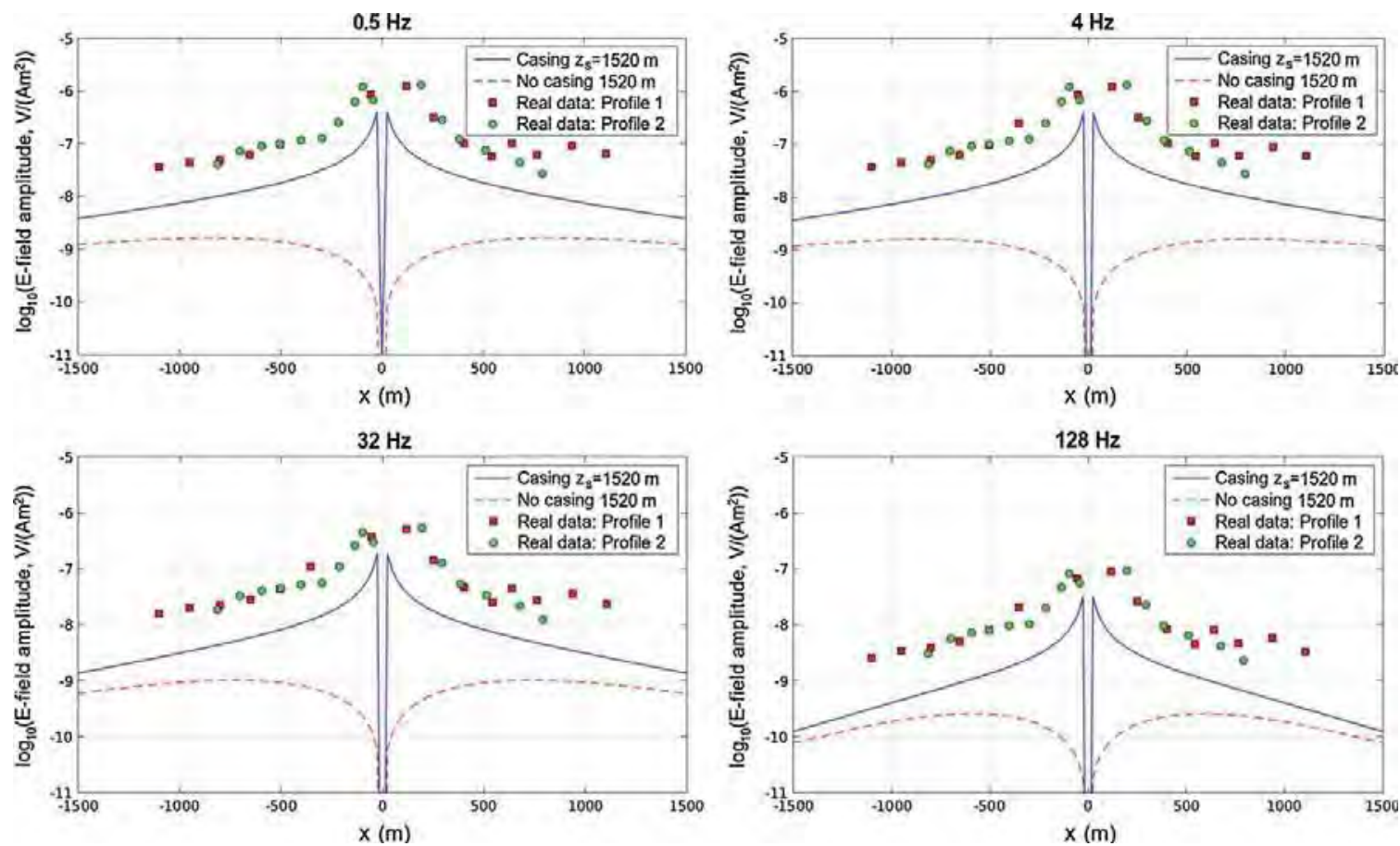

Figure 6 

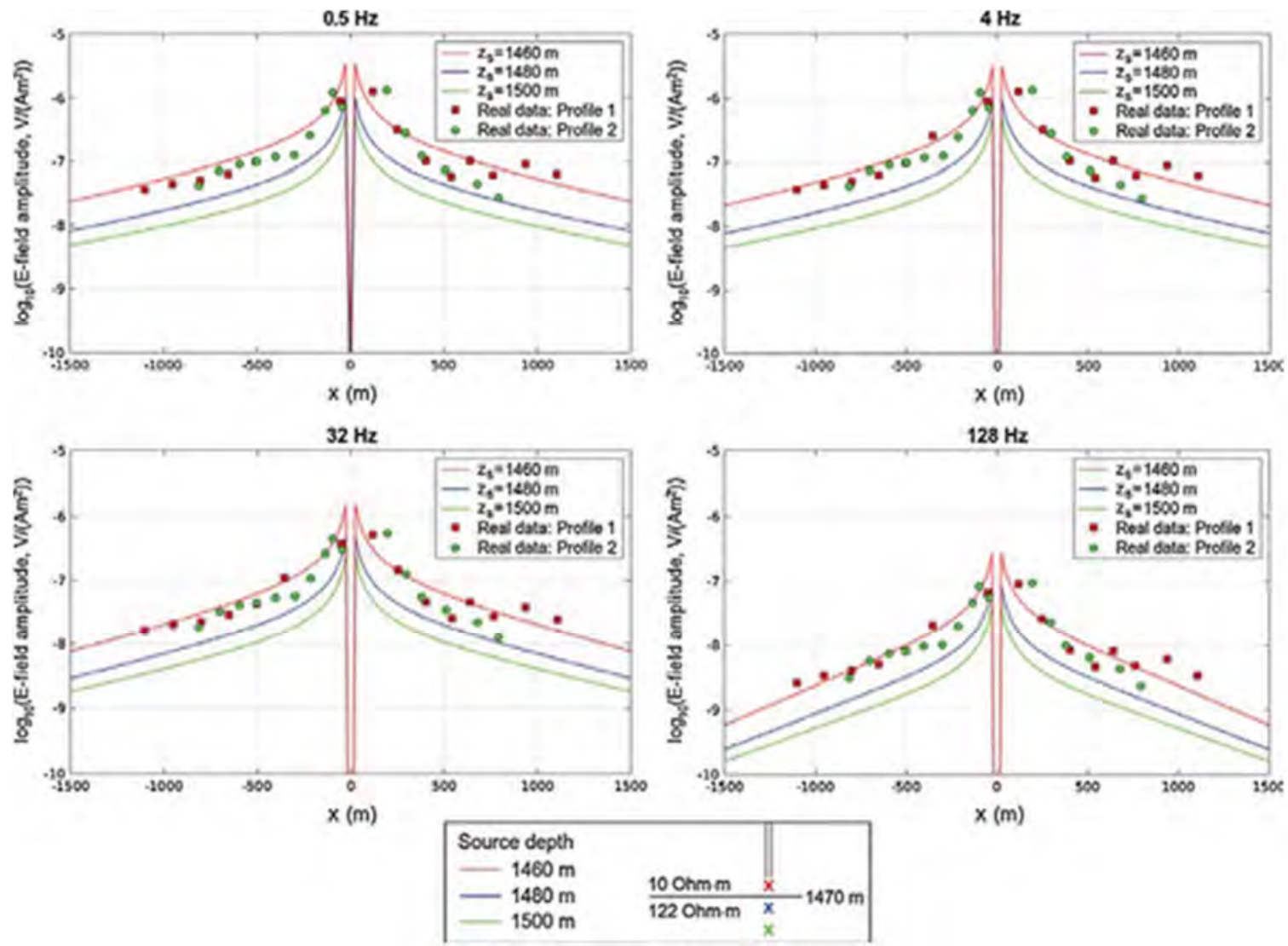

Figure 7 

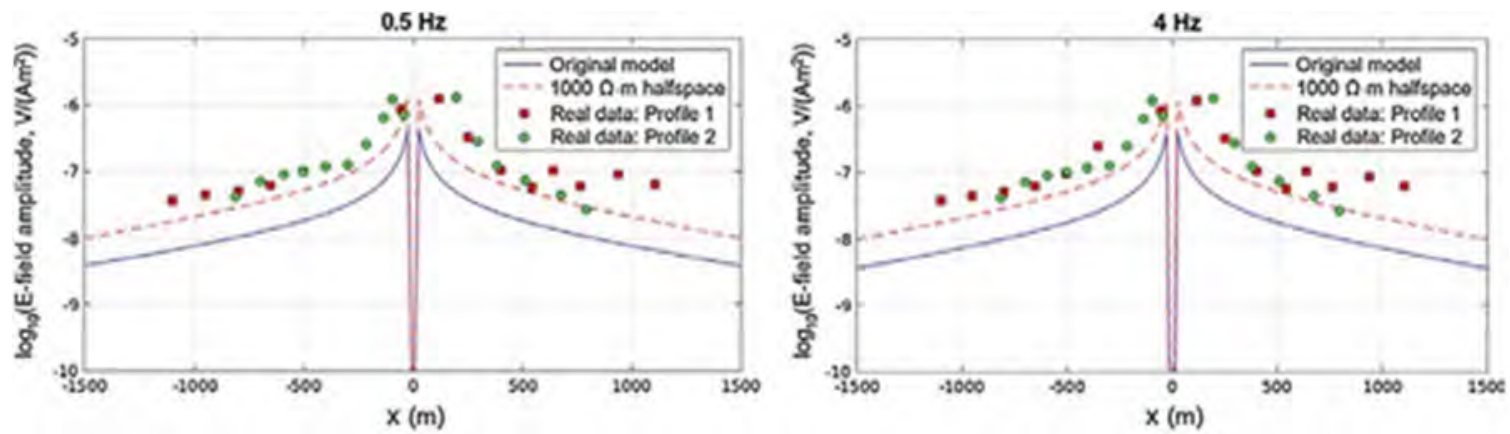

$32 \mathrm{~Hz}$
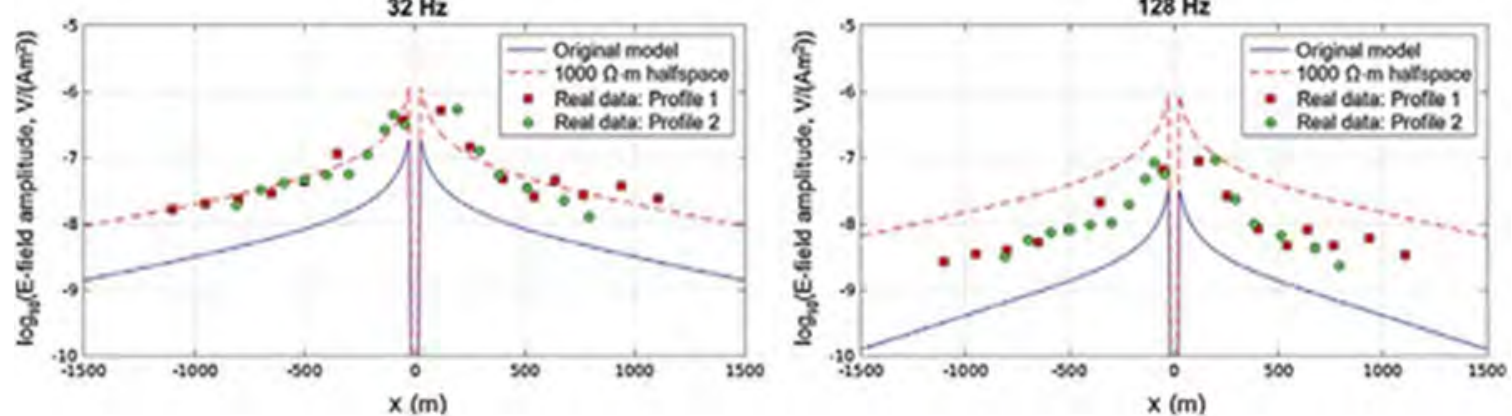

Figure 8 

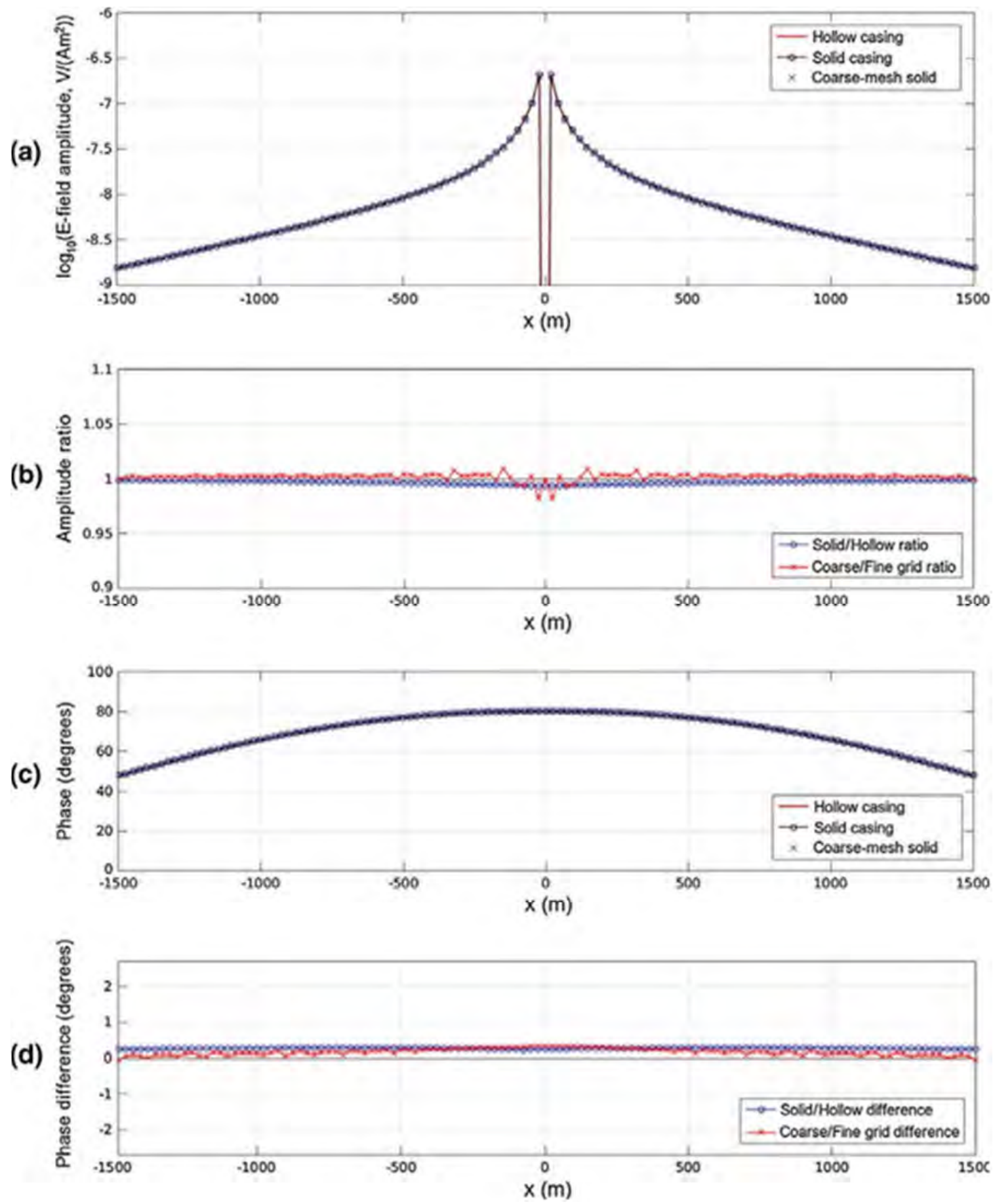

Figure 9 

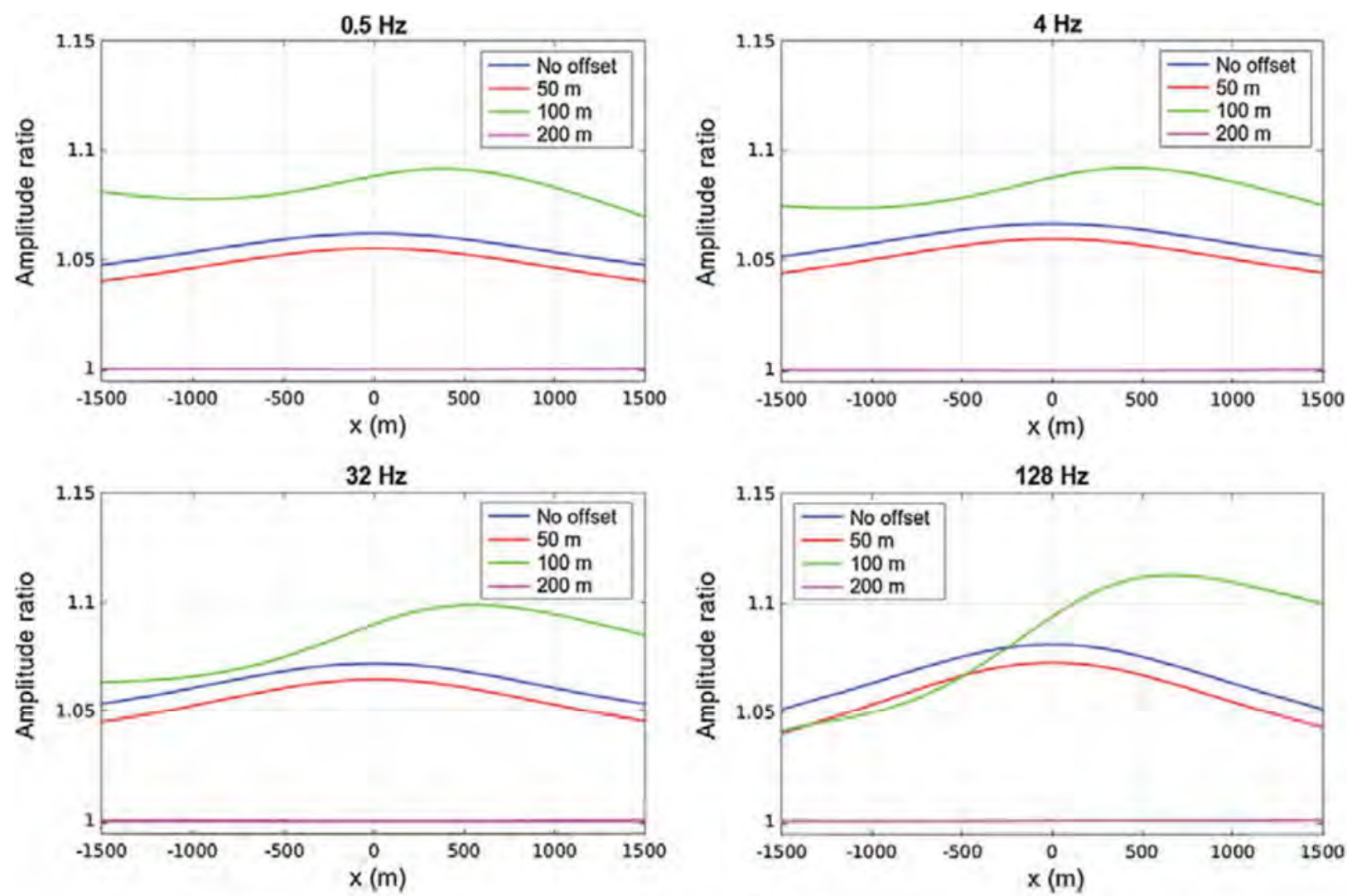

Plume migration
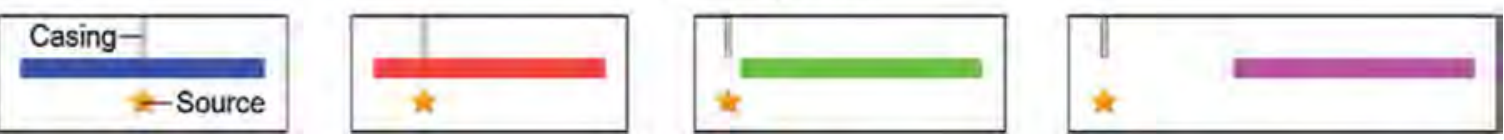

Figure 10 

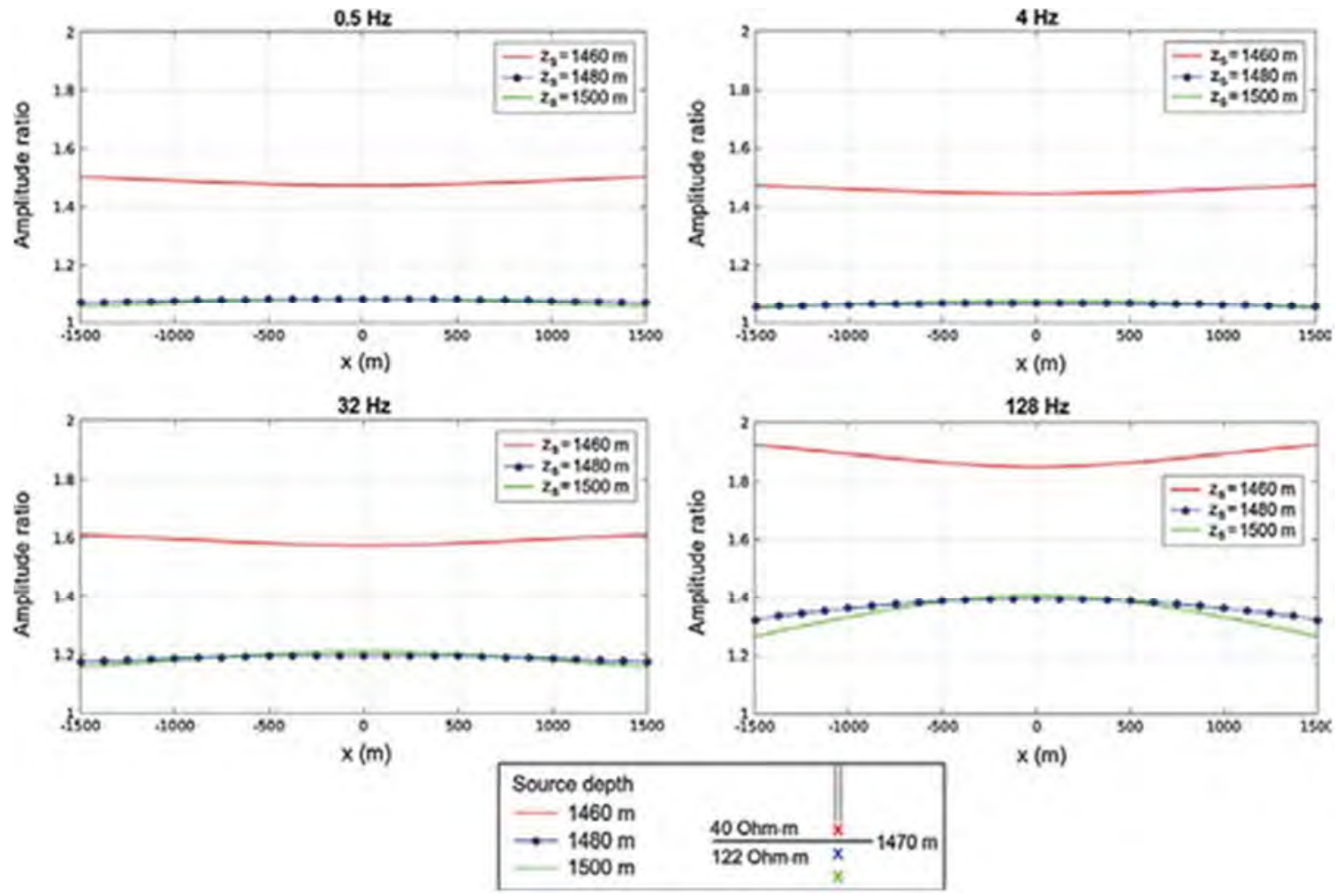

Figure 11 